Jurnal Indonesia Sosial Teknologi: p-ISSN: 2723 - 6609

e-ISSN : 2745-5254

Vol. 2, No. 6 Juni 2021

\title{
KLASIFIKASI MUTU BUAH JAMBU BIJI GETAS MERAH BERDASARKAN TEKSTUR MENGGUNAKAN GREY LEVEL CO-OCCURENCE MATRIX (GLCM) DENGAN KLASIFIKASI KNN
}

\author{
I Gede Wirayudhana \\ Program Studi Informatika, Fakultas Ilmu Komputer Universitas Pembangunan \\ Nasional Veteran Jakarta \\ Email: yd.travelbuddies@gmail.com
}

\begin{abstract}
The purpose of this study was to implement a system capable of classifying the quality of red guava fruit between Super class, A class and B class. Guava fruit is a fruit that contains lots of vitamins and is good for health. Guava also has a high level of demand in Indonesia and has a wide market. This proves that guava is widely consumed by the community and has a high level of competitiveness. So far, the classification of guava quality is done by doing manual observations by looking directly at the outer physical surface of the fruit. This manual classification gives results that are less effective and inconsistent. Digital image processing technology or Image Proseccing can be used to classify the quality of brittle red guava in accordance with the Indonesian National Standard, especially in terms of the outer texture of the guava. This system uses image processing to extract the outer texture features of the guava fruit surface. As a quality classification, themethod is used KNN (K-Nearest Neighbor). This system will classify guava into 3 quality classes, namely super class, A class, and B class. KNN is designed with 4 input features of GLCM value extraction (energy, homogeneity, correlation and contrast) using an angle of $O$ degrees. From the test results, it was found that this classification method was able to provide the best accuracy at $k=9$ in the KNN method with an accuracy of $45.8 \%$.
\end{abstract}

Keyword: technology; leadership; millennials; human Resources; productivity

\section{Abstrak}

Tujuan penelitian ini adalah Untuk mengimplementasikan sistem yang mampu mengklasifikasikan mutu buah jambu biji getas merah antara kelas Super, kelas A dan kelas B. Buah Jambu biji adalah buah yang banyak mengandung vitamin dan baik bagi kesehatan. Jambu biji juga memiliki tingkat permintaan tinggi di Indonesia dan memiliki pasar yang luas. Hal ini membuktikan bahwa jambu biji dikonsumsi oleh masyarakat secara luas dan memiliki tingkat daya saing tinggi. Selama ini pengklasifikasian mutu jambu biji dilakukan dengan melakukan pengamatan manual dengan melihat secara langsung permukaan fisik luar buah. Pengklasifikasian secara manual ini memberikan hasil klasifikasi yang kurang efektif dan tidak konsisten. Teknologi pengolahan citra digital atau Image Proseccing dapat digunakan untuk mengklasifikasikan mutu jambu biji getas merah yang sesuai dengan Standar Nasional Indonesia, terutama dari segi tekstur luar jambu biji. Sistem ini menggunakan pengolahan citra untuk mengekstraksi ciri tekstur luar permukaan 
buah jambu biji. Sebagai klasifikasi mutu digunakan metode KNN (K-Nearest Neighbour). Sistem ini akan mengklasifikasikan jambu biji ke dalam 3 kelas mutu, yakni kelas super, kelas A, dan kelas $\mathrm{B}$,. KNN dirancang dengan masukan 4 fitur ekstraksi nilai GLCM (energy, homogeneity, correlation dan contrast) dengan menggunakan sudut 0 derajat. Dari hasil pengujian didapatkan bahwa metode klasifikasi ini mampu memberikan akurasi terbaik pada $\mathrm{k}=9$ dalam metode KNN dengan akurasi $45,8 \%$.

Kata kunci: teknologi; kepemimpinan; milenial; sumber daya manusia; produktivitas

\section{Pendahuluan}

Saat ini buah jambu biji getas merah (Psidium guajava L.) adalah salah satu komoditas holtikultura yang memiliki minat pasar luas mulai dari pasar tradisional hingga pasar modern. Saat ini tingkat produksi jambu biji di Indonesia pada tahun 2013 mencapai 181.632 ton, pada tahun 2014 mencapai 187.408 ton dan mengalami kenaikan pada tahun 2018 mencapai 228.642 ton (PAMBUDI, 2018). Hal tersebut menunjukkan bahwa buah jambu memiliki daya saing, kualitas mutu buah jambu biji merah dipengaruhi oleh penanganan pasca panen yaitu tingkat ketuaan panen, tekstur, dan daya simpan. Tingkat ketuaan jambu biji ditandai oleh perubahan warna kulit buah (Umah, n.d.). Panen buah jambu biji merah ini terkadang bergantung jarak tempuh daerah pemasaran. Daerah pemasaran yang dekat, buah dipanen saat kulit buah kuning kehijauan, dan mutu buah jambu biji juga dapat dilihat dari segi tekstur yaitu gores, busuk, dan kulit yang terkelupas (Wibowo et al., 2018). (Budianita et al., 2015) melaporkan bahwa buah jambu biji memiliki daya simpan antara 2-7 hari.

Menurut Badan Standarisasi Nasional (Wibowo et al., 2018) jambu biji untuk konsumsi segar digolongkan dalam tiga kelas mutu yaitu kelas super, kelas A, dan kelas $\mathrm{B}$, dalam pengelompokan kelas mutu jambu biji berdasarkan kelas buah Standar Nasional Indonesia (SNI) bertujuan agar para petani jambu biji dapat meningkatkan daya saing pasar dengan kualitas buah terbaik dan preferensi konsumen dalam membeli buah jambu biji mendapatkan kualitas yang baik. (Roidah, 2015) Karena Jambu merah pada umumnya memiliki banyak manfaat dan dapat dijadikan bahan baku bagi industri medis dan bahan baku industri lainnya sehingga penulis akan mengangkat judul tentang klasifikasi jambu biji getas`merah berdasarkan mutu agar diharapkan para konsumen mengetahui mutu buah jambu yang akan dikonsumsinya, dan diharapkan para petani dapat pula menjadikan acuan untuk mengklasifikasikan buah jambu yang dijualnya berdasarkan mutu yang telah ditetapkan oleh Badan Standarisasi Nasional (Prahudaya \& Harjoko, 2017). (Munir, 2004) Penulis membuat penelitian tentang pengolahan citra digital berdasarkan pada acuan standar mutu yang telah ditetapkan oleh Badan Standarisasi Nasional (BSN) dengan tema pengenalan tekstur pada kulit jambu biji getas merah dengan menggunakan metode ekstraksi ciri Gray Level Co-Occurance Matrix (GLCM) dengan menggunakan fitur atau variabel Contrast, Correlation, Energy, Homogeneity dan pengklasifikasian K-Nearest Neighbor (KNN) untuk mengenali jenis 
mutu jambu biji getas merah agar dapat mengklasifikasikan mutu jambu biji getas merah kelas Super, kelas A, dan kelas B.

Tujuan penelitian ini adalah (1) Untuk mengimplementasikan sistem yang mampu mengklasifikasikan mutu buah jambu biji getas merah antara kelas Super, kelas A dan kelas B. (2) Untuk mengetahui cara untuk mengekstraksi ciri pada buah jambu biji getas merah. (3) Untuk mengetahui cara untuk mengklasifikasi jambu biji getas merah. (4) Untuk mengetahui tingkat akurasi dari sistem tersebut. (5) Untuk memberi pengetahuan kepada konsumen dalam membedakan mutu jambu biji getas merah.

\section{Metode Penelitian}

Metode penelitian ini adalah menggunakan metode ekstraksi ciri Gray Level CoOccurance Matrix (GLCM) dengan menggunakan fitur atau variabel Contrast, Correlation, Energy, Homogeneity dan pengklasifikasian K-Nearest Neighbor (KNN) untuk mengenali jenis mutu jambu biji getas merah agar dapat mengklasifikasikan mutu jambu biji getas merah kelas Super, kelas A, dan kelas B.

\section{A. Kerangka Berpikir}

Untuk mencapai tujuan penelitian yang telah dirumuskan dan ditetapkan, maka diperlukan prosedur penelitian sebagai berikut:

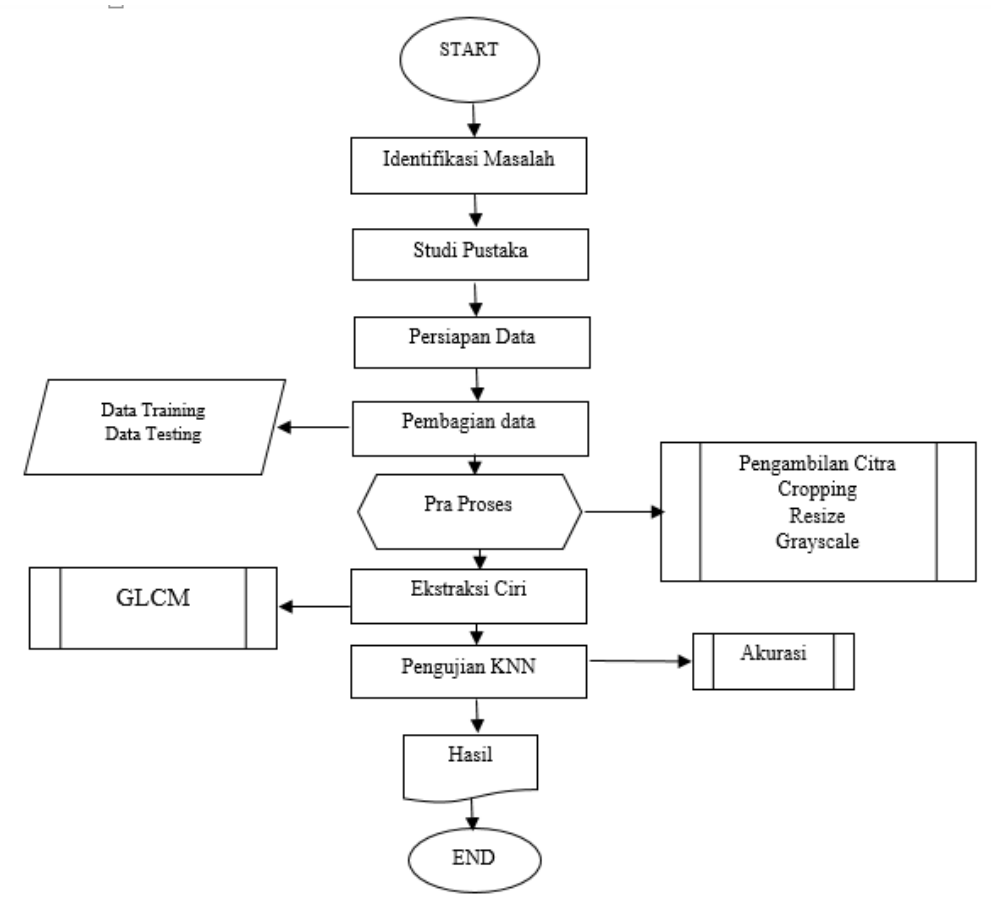

Gambar 1. Kerangka berpikir

\section{B. Praproses Data}

1. Cropping, Tahap cropping ini akan memproses citra awal yang berukuran $4032 \mathrm{x}$ 2268 pixel. Tahap cropping ini akan dilakukan dengan matlab dengan cara 
mengcropping berdasarkan posisi pixel dari citra dan akan dilakukan secara otomatis dengan kordinat cropping yaitu [1465.5 678.5 1021 990] (Santony et al., 2015)

2. Resize, Tahap Resize Citra yang sudah melalui proses cropping dengan $1021 \mathrm{x}$ 990 pixel di resize menjadi 250 x 250 pixel, agar pada saat proses ekstraksi ciri semua citra yang di olah berukuran seragam dan mempercepat proses ekstraksi ciri.

3. Grayscale, Tahap grayscale ini digunakan untuk mengubah citra menjadi citra abu-abu yang selanjutnya akan dilakukan proses ekstraksi ciri.

\section{Ekstraksi Ciri}

Pada tahap ini, data citra yang telah dikelompokan menjadi data Latih dan data Uji akan melalui tahap ekstraksi ciri dengan metode GLCM yang akan mengeluarkan 4 ciri dari citra tersebut (Tarista, 2016). Fitur yang digunakan pada metode GLCM ini meliputi Contrast, Correlation, Energy, Homogeneity, dan menggunakan sudut 0 derajat dengan menggunakan parameter 'Offset' [0 1], alasan dari penggunaan sudut 0 derajat adalah karena citra buah jambu biji tersebut diambil dari arah depan sehingga lebih mudah untuk mengekstraksi dan mengenali tekstur jambu tersebut dengan arah horizontal (Yani, 2017).

\section{Pengujian KNN}

Pada tahap ini, pengujian klasifikasi menggunakan metode $K N N$ (K-Nearest Neighbor) menggunakan data yang telah di kelompokan dan telah diekstraksi cirinya, jarak yang digunakan pada metode ini adalah dengan menggunakan Euclidean distance (Prabowo, 2019).

\section{Hasil dan Pembahasan}

Pada penelitian kali ini akan menggunakan total data 120 citra buah jambu getas merah, data tersebut akan diklasifikasikan berdasarkan mutunya menjadi kelas Super, kelas A, dan kelas B. Kemudian pada penelitian ini data akan dibagi menjadi data Latih dan data Uji. Pembagian data ini akan dibagi menggunakan rasio $80 \%$ data Latih dan $20 \%$ data Uji. Sebelum data dikelompokkan menjadi data Latih dan data Uji, data akan dikelompokan berdasarkan mutunya dahulu atau dikelompokkan berdasarkan kelasnya, dengan pembagian data :

Table 1 Pembagian Kelas

\begin{tabular}{ccc}
\hline Nama Kelas & Kelas & Jumlah \\
\hline 1 & Kelas Super & 40 \\
\hline 2 & Kelas A & 40 \\
\hline 3 & Kelas B & 40 \\
\hline & Total & 120 \\
\hline
\end{tabular}


Tabel diatas merupakan hasil pembagian masing-masing kelas dari 120 data yang telah di akuisisi, yaitu pelabelan pada masing-masing file, jika penamaan file menjadi $1+$ _(nama file) merupakan kelas super, jika 2 + _(nama file) merupakan kelas A, dan $3+$ _(nama file) merupakan kelas B. Pembagian Kelas ini akan dilakukan dengan cara mengubah nama file dengan menambahkan nama kelas di depan nya, contoh : jika nama file asli adalah "120200529_110328.jpg" akan dirubah menjadi "3_120200529_110328.jpg" untuk memberi label kelas 3 atau kelas B. Kemudian setelah 120 file tersebut diberi label yang sesuai pada masing-masing file citra. Data tersebut kemudian akan dikelompokan menjadi data Latih dan data Uji dengan rasio $80 \%$ data Latih, dan $20 \%$ data Uji.

Table 2 Pembagian Data

\begin{tabular}{cccc}
\hline Data & Data Latih & Data Uji & Total \\
\hline Rasio & $80 \%$ & $20 \%$ & $100 \%$ \\
\hline Jumlah & 96 & 24 & 120 \\
\hline
\end{tabular}

Tabel diatas merupakan rasio pembagian data pada data yang telah di akuisisi yaitu $80 \%$ atau 96 citra untuk data latih, dan $20 \%$ atau 24 citra untuk data uji. Kemudian dari data yang telah dibagi antara data latih dan data uji akan dijabarkan kembali kelas apa saja yang terdapat pada masing-masing data latih dan uji, sebagai berikut :

Table 2 Pembagian Data Latih Uji

\begin{tabular}{ccccc}
\hline & Kelas Super & Kelas A & Kelas B & Total \\
\hline Data Latih & 32 & 32 & 32 & 96 \\
\hline Data Uji & 8 & 8 & 8 & 24 \\
\hline
\end{tabular}

Tabel diatas merupakan jumlah data untuk masing-masing data latih dan data uji yang digunakan pada penelitian ini.

\section{Pra Proses}

Pra Proses yang dilakukan dalam penelitian ini yaitu meliputi proses cropping, resize, dan grayscale. Tahap praproses ini akan memproses semua data dari yang telah dikelompokkan. Cropping dilakukan pada citra mentah buah jambu biji dengan cara mengambil hanya bagian foto buah jambu biji saja dan menghilangkan latar belakang atau background, tahap ini dilakukan agar mendapatkan citra jambu biji yang akan digunakan untuk proses ekstraksi ciri, tahap cropping ini akan memproses citra awal yang berukuran 4032 x 2268 pixel. Tahap cropping ini akan dilakukan dengan matlab dengan cara mengcropping berdasarkan posisi pixel dari citra tersebut, yaitu dengan cara imcrop 
I Gede Wirayudhana

(3_20200529_110328,[1465.5 678.5 1021 990]); dengan menggunakan koordinat [1465.5 678.5 1021 990] (Prasetyo, 2011).

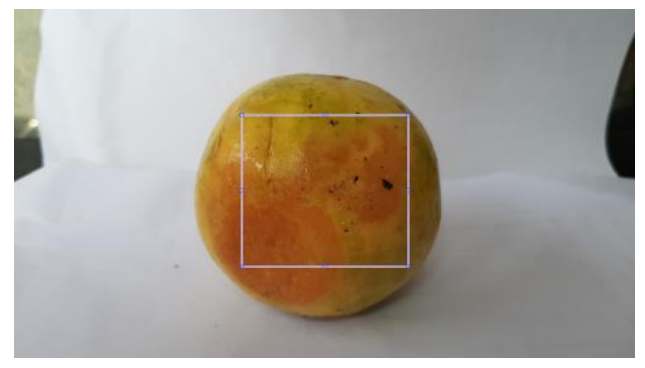

Gambar 2 proses Sebelum Cropping

Gambar 2 diatas merupakan gambar dari radius cropping koordinat [1465.5 678.51021 990].

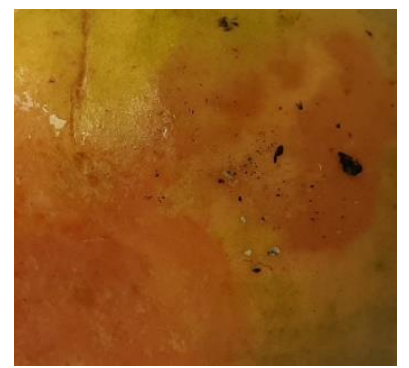

Gambar 3 Proses Sesudah Cropping

Gambar 6 diatas merupakan hasil citra sesudah cropping yang menghasilkan citra berukuran 1021 x 990 pixel.

\section{A. Resize}

Citra yang sudah melalui proses cropping dengan 1021 x 990 pixel di resize menjadi 250 x 250 pixel, agar pada saat proses ekstraksi ciri semua citra yang di olah berukuran seragam. Dengan cara imresize (3_20200529_110328,[250 250]);

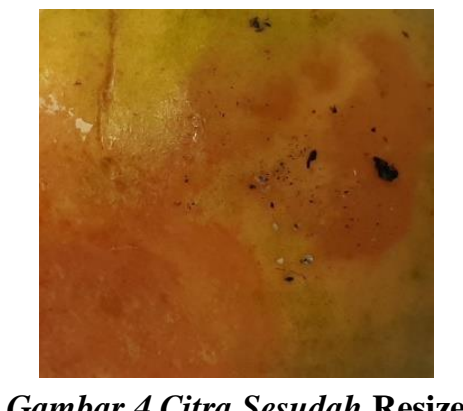

Gambar 4 Citra Sesudah Resize

Gambar 7 diatas merupakan hasil citra yang telah di resize sehingga menghasilkan citra berukuran 250 x 250 pixel. 


\section{B. Greyscale}

Citra yang sudah melalui proses Resize akan di Grayscale dengan menggunakan matlab dengan merubah citra awal berupa citra RGB menjadi citra Grayscale atau citra keabuan. Yaitu dengan cara rgb2gray(3_20200529_110328);

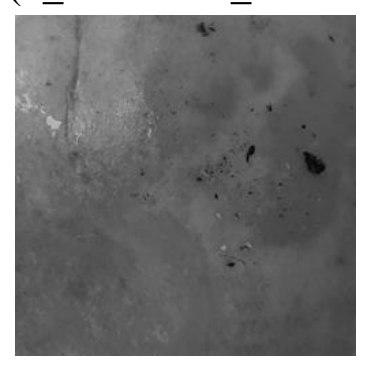

Gambar 5 Citra sesudah Grayscale

Gambar 8 diatas merupakan hasil dari citra yang telah di pra proses grayscale untuk dilanjutkan ke tahap Ekstraksi ciri.

\section{Ekstraksi Ciri}

Pada penelitian ini akan menggunakan ekstraksi citra Graylevel Co-Occurrence Matrix, metode ini akan menghasilkan ekstraksi ciri terhadap seluruh citra yang digunakan. Metode ini akan menggunakan 4 fitur yaitu Contrast, Correlation, Energy, Homogeneity. Dengan menggunakan sudut 0 derajat dengan menggunakan parameter 'Offset' [0 1], sehingga menghasilkan ciri sebagai berikut :

a. Ekstraksi Ciri data Latih

Table 3 Ciri Data Latih

\begin{tabular}{lllll}
\hline Kelas & Contrast & Correlation & Energy & Homogeneity \\
\hline 1 & 0.1591 & 0.8922 & 0.2543 & 0.923 \\
\hline 1 & 0.0659 & 0.9609 & 0.2831 & 0.9675 \\
\hline 1 & 0.0642 & 0.9492 & 0.3009 & 0.9679 \\
\hline 1 & 0.0753 & 0.95 & 0.2777 & 0.9624 \\
\hline 1 & 0.115 & 0.9257 & 0.252 & 0.9433 \\
\hline 1 & 0.0876 & 0.9466 & 0.2772 & 0.9565 \\
\hline 1 & 0.1415 & 0.8554 & 0.3298 & 0.9327 \\
\hline 1 & 0.0634 & 0.9585 & 0.2794 & 0.9684 \\
\hline 1 & 0.127 & 0.9121 & 0.2962 & 0.9383 \\
\hline 1 & 0.1972 & 0.8257 & 0.2807 & 0.9064 \\
\hline 1 & 0.0605 & 0.937 & 0.3583 & 0.9698 \\
\hline 1 & 0.0536 & 0.9585 & 0.3036 & 0.9732 \\
\hline & 0.0899 & 0.9454 & 0.2558 & 0.9553 \\
\hline
\end{tabular}




\begin{tabular}{|c|c|c|c|c|}
\hline 1 & 0.0881 & 0.9371 & 0.2723 & 0.9566 \\
\hline 1 & 0.1081 & 0.8597 & 0.3783 & 0.9484 \\
\hline 1 & 0.1647 & 0.8837 & 0.2566 & 0.9201 \\
\hline 1 & 0.1544 & 0.8499 & 0.305 & 0.9264 \\
\hline 1 & 0.1751 & 0.8339 & 0.2886 & 0.9176 \\
\hline 1 & 0.0841 & 0.958 & 0.2307 & 0.9583 \\
\hline 1 & 0.1419 & 0.7434 & 0.4568 & 0.9309 \\
\hline 1 & 0.1391 & 0.7743 & 0.3798 & 0.9317 \\
\hline 1 & 0.1626 & 0.8569 & 0.2778 & 0.9218 \\
\hline 1 & 0.1178 & 0.9264 & 0.2482 & 0.9424 \\
\hline 1 & 0.0793 & 0.9504 & 0.2657 & 0.9611 \\
\hline 1 & 0.0952 & 0.8483 & 0.4474 & 0.9527 \\
\hline 1 & 0.0762 & 0.934 & 0.3114 & 0.9619 \\
\hline 1 & 0.0647 & 0.9632 & 0.2587 & 0.968 \\
\hline 1 & 0.0677 & 0.9434 & 0.3033 & 0.9664 \\
\hline 1 & 0.0648 & 0.9561 & 0.2801 & 0.9679 \\
\hline 1 & 0.105 & 0.9309 & 0.2557 & 0.9487 \\
\hline 1 & 0.0703 & 0.964 & 0.2605 & 0.9652 \\
\hline 2 & 0.0703 & 0.9732 & 0.2076 & 0.965 \\
\hline 2 & 0.0918 & 0.9396 & 0.2664 & 0.9547 \\
\hline 2 & 0.0725 & 0.9708 & 0.2197 & 0.9641 \\
\hline 2 & 0.1151 & 0.8889 & 0.3395 & 0.9438 \\
\hline 2 & 0.1004 & 0.8978 & 0.3405 & 0.9502 \\
\hline 2 & 0.0817 & 0.9224 & 0.346 & 0.9595 \\
\hline 2 & 0.1526 & 0.9067 & 0.2341 & 0.925 \\
\hline 2 & 0.1029 & 0.9451 & 0.237 & 0.949 \\
\hline 2 & 0.1249 & 0.8993 & 0.2843 & 0.9383 \\
\hline 2 & 0.1238 & 0.9396 & 0.2211 & 0.9388 \\
\hline 2 & 0.1287 & 0.926 & 0.2358 & 0.9359 \\
\hline 2 & 0.1093 & 0.9341 & 0.2452 & 0.9459 \\
\hline 2 & 0.1176 & 0.9047 & 0.2796 & 0.9427 \\
\hline 2 & 0.0594 & 0.9538 & 0.2995 & 0.9703 \\
\hline 2 & 0.0642 & 0.9604 & 0.359 & 0.9682 \\
\hline 2 & 0.0671 & 0.9556 & 0.2748 & 0.9664 \\
\hline 2 & 0.0743 & 0.9153 & 0.373 & 0.9642 \\
\hline 2 & 0.0813 & 0.9512 & 0.2764 & 0.9599 \\
\hline 2 & 0.1257 & 0.9338 & 0.2444 & 0.938 \\
\hline 2 & 0.1138 & 0.9276 & 0.2479 & 0.9441 \\
\hline 2 & 0.0574 & 0.9359 & 0.3827 & 0.972 \\
\hline 2 & 0.1073 & 0.9067 & 0.3628 & 0.9474 \\
\hline
\end{tabular}


Klasifikasi Mutu Buah Jambu Biji Getas Merah Berdasarkan Tekstur Menggunakan Grey Level Co-Occurence Matrix (GLCM) dengan Klasifikasi KNN

\begin{tabular}{|c|c|c|c|c|}
\hline Kelas & Contrast & Correlation & Energy & Homogeneity \\
\hline 2 & 0.1531 & 0.9133 & 0.229 & 0.9259 \\
\hline 2 & 0.1566 & 0.9185 & 0.2099 & 0.9246 \\
\hline 2 & 0.1427 & 0.8793 & 0.274 & 0.9309 \\
\hline 2 & 0.1201 & 0.9453 & 0.2545 & 0.943 \\
\hline 2 & 0.0776 & 0.9495 & 0.2715 & 0.9617 \\
\hline 2 & 0.123 & 0.9408 & 0.2202 & 0.9397 \\
\hline 2 & 0.1022 & 0.9517 & 0.23 & 0.9495 \\
\hline 2 & 0.1134 & 0.933 & 0.2449 & 0.9443 \\
\hline 2 & 0.1404 & 0.8963 & 0.2523 & 0.9317 \\
\hline 2 & 0.0996 & 0.9241 & 0.2917 & 0.9512 \\
\hline 2 & 0.1047 & 0.933 & 0.2811 & 0.9485 \\
\hline 3 & 0.1335 & 0.91 & 0.2716 & 0.9341 \\
\hline 3 & 0.1447 & 0.8796 & 0.2785 & 0.9288 \\
\hline 3 & 0.1334 & 0.8099 & 0.3929 & 0.9345 \\
\hline 3 & 0.1069 & 0.8863 & 0.3654 & 0.9481 \\
\hline 3 & 0.1114 & 0.9562 & 0.2041 & 0.9452 \\
\hline 3 & 0.1341 & 0.8707 & 0.3238 & 0.9347 \\
\hline 3 & 0.1164 & 0.9109 & 0.3063 & 0.9427 \\
\hline 3 & 0.1364 & 0.8938 & 0.2794 & 0.9342 \\
\hline 3 & 0.1064 & 0.9066 & 0.3124 & 0.947 \\
\hline 3 & 0.1377 & 0.8467 & 0.3249 & 0.9328 \\
\hline 3 & 0.133 & 0.9051 & 0.2818 & 0.9351 \\
\hline 3 & 0.1056 & 0.9267 & 0.2837 & 0.9472 \\
\hline 3 & 0.1191 & 0.9092 & 0.2888 & 0.9421 \\
\hline 3 & 0.0849 & 0.9154 & 0.4067 & 0.9584 \\
\hline 3 & 0.0826 & 0.9491 & 0.2709 & 0.9587 \\
\hline 3 & 0.0596 & 0.9716 & 0.276 & 0.9706 \\
\hline 3 & 0.0799 & 0.9547 & 0.2549 & 0.9602 \\
\hline 3 & 0.1488 & 0.9172 & 0.2154 & 0.9267 \\
\hline 3 & 0.2292 & 0.829 & 0.2166 & 0.8928 \\
\hline 3 & 0.0858 & 0.9118 & 0.3942 & 0.9577 \\
\hline 3 & 0.1453 & 0.8851 & 0.2649 & 0.9281 \\
\hline 3 & 0.1233 & 0.9155 & 0.2583 & 0.9396 \\
\hline 3 & 0.108 & 0.9377 & 0.2364 & 0.9465 \\
\hline 3 & 0.0691 & 0.9338 & 0.3286 & 0.9655 \\
\hline 3 & 0.077 & 0.9687 & 0.2267 & 0.9617 \\
\hline 3 & 0.1452 & 0.9056 & 0.2453 & 0.9287 \\
\hline Kelas & Contrast & Correlation & Energy & Homogeneity \\
\hline
\end{tabular}


I Gede Wirayudhana

\begin{tabular}{lllll}
\hline 3 & 0.0652 & 0.9439 & 0.316 & 0.9674 \\
\hline 3 & 0.1264 & 0.9019 & 0.2938 & 0.9386 \\
\hline 3 & 0.0803 & 0.9504 & 0.3003 & 0.9602 \\
\hline 3 & 0.077 & 0.9477 & 0.2805 & 0.9622 \\
\hline 3 & 0.0643 & 0.9559 & 0.2932 & 0.9686 \\
\hline
\end{tabular}

Tabel diatas merupakan hasil dari ekstraksi ciri pada data Latih menggunakan metode GLCM beserta ke-4 nilai GLCM tersebut yaitu nilai contrast, correlation, energy dan homogeneity.

b. Ekstraksi Ciri data Uji

Table 4 Ciri Data Uji

\begin{tabular}{|c|c|c|c|c|}
\hline Kelas & Contrast & Correlation & Energy & Homogeneity \\
\hline 1 & 0.0722 & 0.9558 & 0.2828 & 0.9639 \\
\hline 1 & 0.0947 & 0.9367 & 0.3049 & 0.9533 \\
\hline 1 & 0.0742 & 0.9551 & 0.2758 & 0.9632 \\
\hline 1 & 0.1406 & 0.8717 & 0.3101 & 0.9328 \\
\hline 1 & 0.082 & 0.9634 & 0.2296 & 0.9591 \\
\hline 1 & 0.1033 & 0.9058 & 0.3326 & 0.9487 \\
\hline 1 & 0.075 & 0.9499 & 0.2697 & 0.9626 \\
\hline 1 & 0.0786 & 0.943 & 0.313 & 0.9608 \\
\hline 2 & 0.1085 & 0.919 & 0.2674 & 0.9462 \\
\hline 2 & 0.089 & 0.9385 & 0.269 & 0.9557 \\
\hline 2 & 0.096 & 0.896 & 0.3564 & 0.9531 \\
\hline 2 & 0.1045 & 0.9554 & 0.2287 & 0.9483 \\
\hline 2 & 0.0739 & 0.9306 & 0.35 & 0.9636 \\
\hline 2 & 0.1268 & 0.9132 & 0.2506 & 0.9377 \\
\hline 2 & 0.0862 & 0.921 & 0.3171 & 0.9572 \\
\hline 2 & 0.1167 & 0.8941 & 0.2976 & 0.9423 \\
\hline 3 & 0.0819 & 0.9529 & 0.2537 & 0.9594 \\
\hline 3 & 0.0939 & 0.8754 & 0.4422 & 0.9552 \\
\hline 3 & 0.1763 & 0.8929 & 0.226 & 0.9139 \\
\hline 3 & 0.1338 & 0.9439 & 0.2358 & 0.94 \\
\hline 3 & 0.1386 & 0.8839 & 0.3377 & 0.937 \\
\hline 3 & 0.1818 & 0.8586 & 0.2485 & 0.9116 \\
\hline 3 & 0.1995 & 0.8724 & 0.225 & 0.9031 \\
\hline 3 & 0.088 & 0.9603 & 0.2455 & 0.9569 \\
\hline
\end{tabular}

Tabel diatas merupakan hasil dari ekstraksi ciri pada data Uji menggunakan metode GLCM beserta ke-4 nilai GLCM tersebut yaitu nilai contrast, correlation, energy dan homogeneity. 


\section{Hasil Perhitungan Pengujian Akurasi}

Hasil dari penelitian berikut akan dirangkum dalam subbab berikut ini, pada penelitian kali ini telah didapatkan nilai akurasi tertinggi pada nilai $\mathrm{K}=9$ yaitu dengan akurasi 45,8333\% dan dengan nilai $\mathrm{K}$ terendah yaitu $\mathrm{K}=3$, didapatkan akurasi sebesar $29,1667 \%$.

Table 6 Hasil Akurasi

\begin{tabular}{ccccccc}
\hline Nilai K & 1 & 3 & 5 & 7 & 9 & 11 \\
\hline Akurasi & 41.6 & 29.1 & 37.5 & 37.5 & 45.8 & 41.6 \\
\hline
\end{tabular}

Tabel diatas menjelaskan akurasi pada masing-masing nilai K pada pengujian $K N N$.

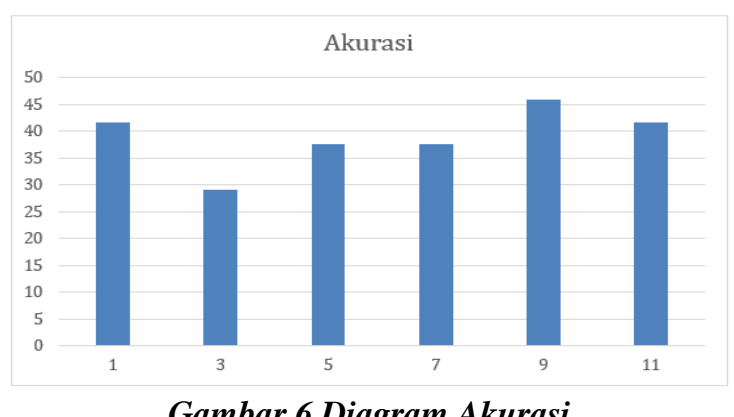

Gambar 6 Diagram Akurasi

Diagram hasil pengujian pada masing-masing nilai $\mathrm{K}$ yang digunakan pada pengujian KNN. Gambar diatas merupakan hasil dari tabel 21 yang telah dibuat bar chart. Persentase tertinggi pada klarifikasi Tingkat mutu buah jambu biji terdapat pada $K=9$ dengan nilai 45,8\%. Akurasi yang tergolong kecil ini besar kemungkinan karena tahap akuisisi data yang tidak sesuai dengan masing-masing kelas Super, kelas A, dan kelas B, sehingga mendapatkan akurasi yang minim, dan besar kemungkinan karena tahap praproses masih kurang optimal.

\section{Kesimpulan}

Berdasarkan pemaparan diatas dapat disimpulkan yaitu KNN mampu mengidentifikasi serta mengklasifikasikan mutu buah jambu biji getas merah dengan menggunakan 4 fitur yaitu Energy, Homogenity, Contrast, Correlation dengan menggunakan sudut 0 derajat, dan Persentase tertinggi pada klarifikasi Tingkat mutu buah jambu biji terdapat pada $\mathrm{K}=9$ dengan nilai 45,8\%. Akurasi yang tergolong kecil ini besar kemungkinan karena tahap akuisisi data yang tidak sesuai dengan masing-masing kelas Super, kelas A, dan kelas B, sehingga mendapatkan akurasi yang minim. 


\section{Bibliography}

Budianita, E., Jasril, J., \& Handayani, L. (2015). Implementasi Pengolahan Citra dan Klasifikasi K-Nearest Neighbour Untuk Membangun Aplikasi Pembeda Daging Sapi dan Babi Berbasis Web. Jurnal Sains, Teknologi Dan Industri, 12(2), 242-247.

Munir, R. (2004). Pengolahan citra digital dengan pendekatan algoritmik.

PAMBUDI, A. A. (2018). Sortasi Dan Grading Cabai Merah (Capsicum annuum L.) Menggunakan Pengolahan Citra Digital. Universitas Gadjah Mada.

Prabowo, H. (2019). IDENTIFIKASI JENIS BIJI KOPI ARABIKA DAN ROBUSTA MENGGUNAKAN DETEKSI TEPI CANNY DENGAN KLASIFIKASI K-NEAREST NEIGHBOR. Universitas Pembangunan Nasional Veteran Jakarta.

Prahudaya, T. Y., \& Harjoko, A. (2017). Metode Klasifikasi Mutu Jambu Biji Menggunakan Knn Berdasarkan Fitur Warna Dan Tekstur. Jurnal Teknosains, 6(2), $113-123$.

Prasetyo, E. (2011). Pengolahan citra digital dan aplikasinya menggunakan Matlab. Yogyakarta: Andi.

Roidah, I. S. (2015). Pemanfaatan lahan dengan menggunakan sistem hidroponik. Jurnal Bonorowo, 1(2), 43-49.

Santony, J., Harlan, J., \& Madenda, S. (2015). Segmentasi Citra X-Ray Thorax Untuk Mengidentifikasi Objek Infiltrat Dengan Proses Morfologi Matematika. Prosiding Senatkom, 1 .

Tarista, M. P. (2016). DETEKSI KANKER PAYUDARA PADA CITRA MIKROKALSIFIKASI MAMMOGRAFI DENGAN METODE NAIVE BAYES. UNIVERSITAS AIRLANGGA.

Umah, S. K. (n.d.). Kajian Mutu Buah Jambu Biji Merah (Psidium guajava L.) Berdasarkan Variasi Umur Simpan Menggunakan Pengolahan Citra Digital.

Wibowo, F., Hakim, D. K., \& Sugiyanto, S. (2018). PENDUGAAN KELAS MUTU BUAH PEPAYA BERDASARKAN CIRI TEKSTUR GLCM MENGGUNAKAN ALGORITMA K-NEAREST NEIGHBORS. Jurnal Nasional Pendidikan Teknik Informatika: JANAPATI, 7(1), 100-106.

Yani, D. U. R. (2017). Klasifikasi Tingkat Keparahan Non-Proliferative Diabetic Retinopathy Berdasarkan Hard Exudate Menggunakan Extreme Learning Machine. Institut Teknologi Sepuluh Nopember. 